\title{
Hemi-Central Retinal Vein Occlusion Secondary to the Habit of Forceful Sneeze Prevention
}

\author{
Seref Istek* \\ Usak University, Turkey
}

Submission: June 18, 2017; Published: July 17, 2017

*Corresponding author: Seref, Usak University, Faculty of Medicine Training Hospital Eye Clinic Fevzi Çakmak Mahallesi, Ușak City, 64000, Ușak Turkey, Email: drsistek@hotmail.com

\section{Introduction}

31 year-old man applied to the eye clinic with a complaint of silhouette in the lower paracentral visual field on his left eye. His central visual acuity was $10 / 10$ both on his eyes. Fundus examination revealed hemi-central vein occlusion sparing the macula. A few days later widespread intra-retinal hemorhages fell into macula and visual acuity reduced dramatically. Detailed story of the patient pointed out that he had a lomber disc herniation 3 months ago at L3-L4 levels. Detailed history also showed that the patient had hypertrophic adenoids and hypertrophic nasal conc has which are under treatment by nasal decongestants. The patient did not have a heavy conditional work. But it had been speculated that powerful prevention and keeping the sneeze resulted both the herniation and hemi-central vein occlusion. Vein occlusions are common among olders but systemic disorders must be ruled out in youngers. We intended to share acute intra-ocular pressure increase as an uncommon cause for vein occlusion in this dramatic young man because systemic disease research came clean. Lomber herniation usually occurs secondary to forcing the inter-vertebral discs to high pressures that they can endure. So they can rupture and cause disc herniation. Performing valsalva maneuver by coughing, sneezing or sneeze prevention may increase pressure inside the medulla spinalis so it can result as disc herniation. This maneuver not only affects on the intervertebral discs, but also on all intra- and extra-dural structures and nerves [1]. So optic nerve head may be affected as an intra-dural component.

Hemi-central retinal vein occlusions which are classified in central retinal vein occlusion may result from hypertension, diabetes, atherosclerosis, hyper coagulable states and hypercholesterolemia. Younger patients with hemi-central retinal vein occlusion must be ruled out from diseases mentioned above. Valsalva manoeuver is the forced exhalation against a closed glottis. First described by an Italian anatomist in 17th century Antonio Maria Valsalva, it is now a well known entity amongst medical practitioners. It leads to increased intrathoracic and intra-abdominal pressure and raised central venous pressure. It is an uncommon condition and has been reported to occur with various forms of Valsalva stress such as weight lifting, physical exercise, balloon blowing, birth labour [2]. Sneezing prevention may be accepted as a rare cause of valsalva stress. Preretinal haemorrhage caused by this sudden rise in venous pressure was first termed as Valsalva haemorrhagic retinopathy by Duane TD in 1972 [3]. Valsalva retinopathy is typically seen in young males. Sometimes it may make a fluid level which's location can be subinternal limiting membrane (ILM) or subhyaloid. Duane [3] first postulated the mechanisms for retinopathies due to distal trauma as alteration in arterial circulation (forward retinopathy), venous circulation (backward retinopathy) or to changes occurring in both systems (mixed retinopathy). Valsalva retinopathy may look like vein occlusions in appearance as spreaded intraretinal haemorrhages but transformation of valsalva retinopathy to vein occlusion related macular edema is a rare antity. Here i report a case about valsalva retinopathy which transformed to complete hemi-central vein occlusion in a week.

\section{Case Presentation}

A 31 year-old healthy man complained about a blurry silhouette in the lower para-central visual field in his left eye after a powerfull sneeze prevention. Ophthalmic examination revealed bilateral 10/10 visual acuities and normal ocular tensions. Detailed examination showed a hemi-central vein occlusion sparing macula in the left fundus. There were widespread intra-retinal haemorrhages diffused in the upper hemicentral retina and a pre-retinal and subhyaloid haemorrhage just near the temporal macula. The fundus view is seen in Figure 1. Questioning about heavy work conditions for probable valsalva maneuver indicated a sneeze prevention habit. He had a lomber disc herniation at the L3-L4 levels 3 months ago 
and hypertrophic adenoids and nasal conchas which were still being treated by nasal decongestants. Lomber disc herniation is seen in Figure 2. Sneeze prevention habit was accused for lomber disc herniation by neuro-surgeon. After a week of rest recommendation and conservative management for valsalva retinopathy, the haemorrhages came to the bottom of macula and clinical macular edema settled upon as his visual acuity decreased to $3 / 10$. Intravitreal bevacizumab injection was performed in other eye center at second week and he had full visual recovery again in two weeks time after the injection.
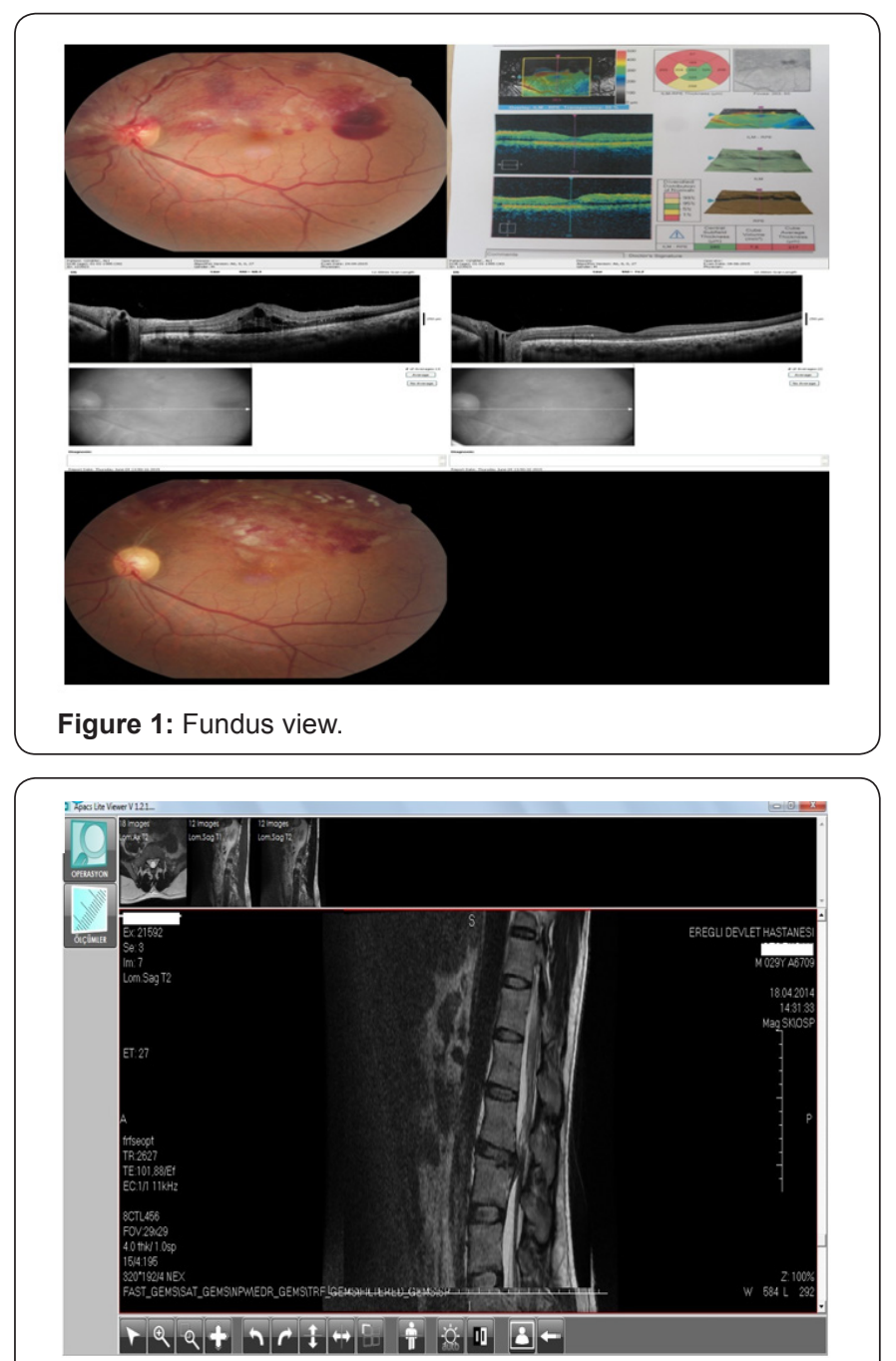

Figure 2: Lomber disc herniation.

There were no retinal holes, tears, detachment, perivascular sheathing or snow banking at parsplana. Vein occlusions were not common among youngers so investigations including complete blood counts, clotting parameters such as antithrombin, protein $\mathrm{c}$, protein $\mathrm{s}$, d-dimer, factor 5 , biochemical parameters such as urea, creatinine and glucose, crp, sedimentation were normal. Systemic evaluation was carried out by the physician and no abnormality was detected. We diagnosed him as hemi-central vein occlusion secondary to valsalva retinopathy. Systemic clotting abnormalities must be ruled out in hemi-central retinal vein occlusion among youngers. Disc herniation without predisposing factor and vein occlusion after sneeze prevention steered us to think about valsalva retinopathy. Intravitreal bevacizumab injection was performed and laser photocoagulation was performed for the macular edema secondary to hemi-central retinal vein occlusion. Because of the valsalva retinopathy was not limited to the pre-retinal and sub-hyaloid area, a week later the haemorrhages were spreaded widely to the macula and macular edema was settled. The visual acuity of the patient decreased to $3 / 10$ snellen on the left and conservative treatment modality for the valsalva haemorrhagic retinopathy was replaced by the treatment of macular edema secondary to hemi-central retinal vein occlusion.

\section{Results}

The visual acuity of the patient is $10 / 10$ on both eyes with complete resolution of macular edema for 2 months. Ghost vessels are seen on fundus examination and retinal haemorrhages are just about to resolve. These are seen in Figure 1. Bed rest and avoiding from valsalva maneuvers were adviced for lumbar disc herniation.

\section{Discussion}

Valsalva retinopathy is a unilateral or bilateral condition which occurs by rupture of superficial retinal capillaries. Heavy lifting, straining, coughing or vomiting may cause it. Valsalva maneuvers typically result in superficial retinal haemorrhages(sub-internal limiting membrane, subhyaloid) with a predilection for the macula, but subretinal, retinal and vitreous haemorrhages have been reported. The prognosis is variable, however complete visual recovery is possible [4]. Some patients may develop a poor visual outcome due to the presumed toxic effects of dense premacular haemorrhages on the retinal pigment epithelium and/or epiretinal membrane formation. Nd-YAG laser puncture of the posterior aspect of the vitreous may allow drainage of premacular haemorrhage or vitrectomy may be performed in selected cases [4]. It may also managed conservatively with good outcomes. It may Valsalva retinopathy is a self-limited condition. Recurrence of valsalva retinopathy can be encountered if preventing any condition leading to valsalva like stress is not succeeded [2]. Our patient did not know about the harmful effects of sneeze prevention. A careful history is the key to the diagnosis. The prognosis is good and patient needs to be counselled to avoid any such Valsalva manoeuver like stress to prevent recurrence in future. Habits which are against the physiology such as sneeze prevention may be harmful. Patients should be careful in every physical activities which may induce valsalva maneuver. Valsalva retinopathy may be seen as central or hemi-central retinal vein occlusion.

\section{References}

1. Cecin HA (2010) Cecin's Sign ("X" Sign): improving the diagnosis of radicular compression by herniated lumbar disks. Revista brasileira de reumatologia 50(1): 44-55. 
2. Waikar S, Srivastava VK (2013) Valsalva retinopathy in a young healthy individual. Med J Armed Forces India 69(2): 193-195.

3. Duane TD (1972) Valsalva hemorrhagic retinopathy. Trans Am Ophthalmol Soc 70: 298-313.
4. El-Defrawy H, Sallam A, McKechnie CJ, Zambarakji H (2011) Valsalva retinopathy in pregnancy. Should we treat? JRSM short Rep 2(6): 45.
Your next submission with Juniper Publishers will reach you the below assets

- Quality Editorial service

- Swift Peer Review

- Reprints availability

- E-prints Service

- Manuscript Podcast for convenient understanding

- Global attainment for your research

- Manuscript accessibility in different formats

( Pdf, E-pub, Full Text, Audio)

- Unceasing customer service

Track the below URL for one-step submission https://juniperpublishers.com/online-submission.php 